\title{
In vivo social regulation of high-risk parenting: A conceptual model of Parent-Child Interaction Therapy for child maltreatment prevention
}

\author{
Elizabeth A. Skowron ${ }^{1}$ \\ Beverly W. Funderburk² \\ ${ }^{1}$ Department of Psychology \& Center for Translational Neuroscience \\ University of Oregon \\ ${ }^{2}$ Department of Developmental and Behavioral Pediatrics \\ University of Oklahoma Health Sciences Center
}

In Press, Children and Youth Services Review

Correspondence concerning this article should be addressed to Elizabeth Skowron, University of

Oregon, 437 Straub Hall, Eugene, OR 97401. Telephone number: 541-346-9329. Email:

eskowron@uoregon.edu

Acknowledgements:

Financial Support. This research was funded by the National Institutes of Health through National Institute on Drug Abuse Grant R01-DA036533. 


\begin{abstract}
Meta-analyses show that Parent-Child Interaction Therapy (PCIT) significantly reduces child abuse and neglect in families where maltreatment has already occurred; however, research into the underlying mechanisms of change (i.e., how PCIT effects positive changes in parenting) remains limited. In this article, we discuss a new conceptual model of PCIT's active ingredients that is informed by biobehavioral research documenting the physiological underpinnings of problematic parenting. We describe deficits in self-regulation observed in child maltreating parents and PCIT's unique live coaching approach and associated techniques that may form the basis for in-vivo social regulation in the act of parenting that supports more effective, positive parenting behavior, strengthens parents' self-regulation skills, and reduces child maltreatment.
\end{abstract}




\section{Introduction}

A leading cause of death among young children ages 1 to 4 in the United States, child maltreatment (CM) is a serious public health problem that affects 1 in 7 U.S. children each year and results in substantial social and economic costs to society (Centers for Disease Control and Prevention,

\section{https://www.cdc.gov/violenceprevention/childabuseandneglect/fastfact.html; U.S. Department of Health \&} Human Services, Administration for Children and Families, 2020). CM-exposed children are more likely to develop anxiety, heightened stress reactivity, emotion dysregulation, hypervigilance, externalizing disorders, difficulties with school adjustment, and require special education services (Cicchetti \& Toth, 2005; Gunnar \& Fisher, 2006; Lavi et al., 2019; Shakman, Shakman, \& Pollak, 2007; Skowron et al., 2014; Tarullo \& Gunnar, 2006). Statistics show that parents are involved in most documented cases of child physical abuse and neglect (e.g., 77.5\% in 2018; U.S. DHHS., 2020), often resulting in out-of-home placements that have enormous costs at the family, community, and societal level. Thus, parents and caregivers represent critically important targets for intervention in order to lower the incidence rates for child abuse, avoid family disruptions, support family preservation, and to prevent transmission of $\mathrm{CM}$ across generations in families. Yet few parenting interventions have been shown to be effective at reducing rates of $\mathrm{CM}$ perpetration in caregivers who already have a history of CM (Euser et al., 2015; Kennedy et al., 2016; Skowron \& Reinemann, 2005).

Parent-Child Interaction Therapy (PCIT) is one promising evidence-based intervention that has been documented in several clinical trials to significantly reduce $\mathrm{CM}$ recidivism in families where $\mathrm{CM}$ has already begun (Chaffin, Silovsky, Funderburk, Valle, Brestan, et al., 2004; Chaffin, Funderburk, Bard, Valle, \& Gurwitch, 2011; Thomas \& Zimmer-Gembeck, 2011, 2012), findings further supported by meta-analyses (Euser et al., 2015; Kennedy et al., 2016). PCIT has been recognized by the Prevention Services Clearinghouse, which was developed under the auspices of the Families First Preservation Act (Title IV-E Prevention Services Clearinghouse; https://preventionservices.abtsites.com, 2019), as a treatment well-supported for prevention of out-of-home placements due to $\mathrm{CM}$, and the treatment has been recognized by a number of other registries or guides (e.g., 
Aos, Lee, Drake, et al., 2011; California Evidence-Based Clearinghouse for Child Welfare;

https://www.cebc4cw.org; Kaufman Best Practice Project, 2004; Lee et al., 2012) as a highly effective and costeffective treatment for $\mathrm{CM}$. Despite strong support for reducing $\mathrm{CM}$, little research has examined the means by which changes wrought by PCIT take place or are sustained.

Initial research on PCIT with the Child Welfare (CW) population focused on using PCIT to treat childmaltreating parents rather than families of children with disruptive behavior as had been the focus of prior PCIT research. The goal was to establish whether PCIT could be effective in reducing the likelihood of future reports in families with a confirmed case of physical abuse (often in conjunction with physical neglect). In the first randomized controlled trial of families with a history of confirmed CM (Chaffin et al., 2004), PCIT combined with motivational enhancement prework (ME) decreased rates of re-abuse up to 3 years post-treatment to only $19 \%$ (compared to $50 \%$ for services-as-usual). That study demonstrated that caregivers learned the parenting skills targeted in PCIT, presumably leading to the reduced CM risk, but extensive examination of changes in the caregiver or child that accounted for the demonstrated effects was beyond the scope of the project. A subsequent randomized controlled trial moved the treatment delivery to community service providers rather than a university clinic and expanded the treatment population to open enrollment at a community agency, which included many child welfare-involved families seeking reunification after a history of child physical abuse, child neglect, or a combination of the two (Chaffin et al., 2011). Findings again demonstrated strong reductions in risk for future reports of $\mathrm{CM}$, along with decreases in observed negative parenting behavior and increases in positive parenting practices. Clinical trials of PCIT conducted in Queensland, Australia with child welfareinvolved families also achieved significant reductions in risk for child abuse, negative parenting and parenting stress, along with large gains in positive parenting (Thomas \& Zimmer-Gembeck, 2011, 2012). However, finegrained analysis of mechanisms of change in the caregiver or in the child were beyond the scope of each of these four studies. 
Subsequently, Chaffin and colleagues later conducted a sequential process analysis of session-by-session changes in the first phase of PCIT for a subset of child welfare-involved families enrolled in the first clinical trial. At treatment outset, parents were equally likely to respond to positive child behaviors with positive or negative parenting (Hakman, Chaffin, Funderburk, \& Silovsky, 2009). However over time, PCIT quickly led to significant reductions in aversive responding and corresponding increases in positive parenting in response to children's positive behavior. These early findings suggest that PCIT interrupts the coercive cycle and results in greater positive coordination or parent-child behavioral synchrony in caregiver-child interactions (Hakman, et al., 2009). More recent studies are documenting PCIT's positive effects on caregivers extend to reductions in caregiving stress (Thomas, Abell, Webb, Avdagic, \& Zimmer-Gembeck, 2017), and improvements in survey reports of emotion regulation (Lieneman et al., 2020).

Yet despite promising evidence of its effects on reducing further risk for child maltreatment among child welfare families, limited knowledge exists about how PCIT works with families involved in the child welfare system. Drawing on what is known about caregiving in $\mathrm{CW}$ versus non-CW populations, we articulate a theory about some mechanisms of change in PCIT that may be mobilizing significant gains in families involved in child welfare: We are currently testing these ideas in a randomized clinical trial with the support of NIH/NIDA funding (Nekkanti et al., 2020). As we describe below, the significant improvements that PCIT achieves in the quality of CW parent-child interactions and $\mathrm{CM}$ risk reduction suggest to us that PCIT helps to correct regulatory impairments and alter maladaptive social cognitions that fuel aversive parenting in child welfare-involved families.

\section{Child Maltreatment, Parenting \& Modifiable Risks}

Many factors contribute to the perpetration of child maltreatment (CM), including parents' own caregiving histories, chronic stress exposure, deficits in emotion regulation and self-control, parent psychopathology including substance abuse, family and community violence, and a host of other contextual stressors (Belsky, 1993; Cicchetti \& Toth; 2005; Rogosh, Cicchetti, Shields, \& Toth, 1995; Skowron \& Woehrle, 
2012; Trickett, Aber, Carlson, \& Cicchetti, 1991). Parents' own developmental histories of harsh caregiving increase risk for them to maltreat their own children, enter violent relationships, and suffer serious psychopathology (Barth, 2009; Belsky, Conger, \& Capaldi, 2009; Kaufman \& Zigler, 1989; see meta-analysis by Assink, Spruit, Schuts, Lindauer, van der Put, \& Stams, 2018). Caregivers who perpetrate CM display gaps in their knowledge of basic parenting skills, tend to rely on aversive child management strategies and deprive their children of adequate emotional and physical attachments necessary for optimal development (e.g., Khoury et al., 2020; Wilson, Rack, Shi, \& Norris, 2008). Caregivers involved with CW are more hostile, intrusive, and controlling, less affectionate, and also are more passive, disengaged, and less likely to initiate positive interactions with their children relative to non-CW-involved caregivers (Burgess \& Conger, 1978; Skowron et al., 2011; Wilson et al., 2008). Further, caregivers at high risk for CM are more likely to initiate ruptures while parenting, and less likely to initiate repairs with their children, than those who are at lower risk for CM (Skowron, Kozlowski, \& Pincus, 2010).

Impairments in self-regulation constitute a significant contributing risk factor for problem parenting (Rogosch, Cicchetti, \& Aber, 1995; Skowron et al., 2015) and play a central role in substance abuse and other disorders of regulation (Suchman, Pajulo, \& Mayes, 2013). Caregivers at risk for perpetrating CM show heightened stress reactivity, and deficits in emotion regulation and self-control that interfere with their efforts to parent in positive, responsive ways and fuel coercive process. Caregivers at highest risk for $\mathrm{CM}$ are more emotionally and physiologically reactive, emotionally dysregulated, and likely to emotionally distance or cut off from others when under stress (McCanne \& Hagstrom, 1996; Wells, Skowron, Scholtes, \& DeGarmo, 2020; Skowron et al., 2013). This is important because the ability to regulate one's emotions, attention, and behavior underlie capacities to provide safe, warm, and responsive parenting (e.g., Denham et al., 2000; Joosen, Mesman, Bakermans-Kranenburg, \& van IJzendoorn, 2013; Skowron \& Woehrle, 2012). Good emotional and behavioral self-control involves inhibiting one's automatic or typical responses, and instead, engaging in a more intentional response. Thus, for example, a parent who is quick to criticize or direct their child may learn to inhibit those 
responses and instead, watch for and praise their child's appropriate behavior. Parents with good attention control can focus their attention on an aspect of their child's behavior that they might typically overlook rather than allowing their focus to be drawn to negative behavior (e.g., noticing that siblings are sharing rather than that they are making a mess with the toys). These can be difficult skills for any caregiver, let alone those who have a history of perpetrating CM.

Maladaptive social cognitive processes reflect another hallmark of caregivers who struggle with child abuse and neglect (Bugental, 2009; Skowron \& Woehrle, 2012). Such caregivers tend to be self-critical (Skowron et al., 2010), report lower confidence in their parenting skills (Brown, Cohen, Johnson, \& Salzinger, 1998), and experience parenting as less rewarding than parents at lower risk for CM (Rutherford, Williams, Moy, Mayes, \& Johns, 2011). Caregivers at risk for perpetrating CM also display negative, threat-sensitive attributions about their children, that is, they tend to see themselves as victims in the parent-child relationship, and believe that problem interactions are due to factors within their children's control and out of their own control (Bugental, 2009; Pidgeon \& Sanders, 2009). For example, caregivers may believe their infant is acting stubborn or willful, rather than communicating distress, thus perceiving the infant's bids as negative and threatening, rather than a bid for supportive caregiving. These threat-sensitive cognitions lead them to take self-protective, overly harsh stances toward their children, and engage in aversive parenting, leading to greater risk for CM perpetration (Bugental et al., 1993; Bugental, 2009; Martorell \& Bugental, 2006). Together, deficits in emotion regulation, self-control of attention and behavior, and these maladaptive social cognitive processes lay the groundwork for coercive parenting cycles and make it difficult for caregivers to experience themselves as effective, nurturing parents (Granic \& Patterson, 2006; Skowron, 2015), increasing risk for CM.

Our research has documented tight coordination between CM-exposed children's bids for support and caregivers' peripheral physiology (Wells, Skowron, Scholtes, \& DeGarmo, 2020), and between caregiver physiology and their subsequent parenting behavior (Skowron, Cipriano-Essel, Benjamin, Pincus, \& Van Ryzin, 2013), suggesting that positive parenting may be uniquely physiologically taxing for mothers who perpetrate 
physical child abuse. Specifically, findings show that abusive mothers experience increased arousal in response to increases in their children's prosocial compliance behaviors and when engaged in warm, responsive parenting: The heightened arousal they experienced led abusive mothers to become harsh and controlling toward their child only moments later (Wells et al.; Skowron et al.). This is in contrast to non-abusive mothers who responded to their children's prosocial behaviors with increased physiological calm (i.e., increased RSA), for whom physiological arousal is not a trigger for harsh or rejecting parenting behavior. These findings suggest that (a) efforts to teach positive parenting skills may not be successful for caregivers who experience positive parentchild interactions as stressful and a trigger for harsh control parenting, and (b) this triggering may shed insights into the durability of aversive parenting in high-risk families. Further, these regulatory deficits and maladaptive social cognitions heighten risk for treatment dropout in child welfare-involved families (Skoranski, Skowron, Nekkanti, Scholtes, Lyons, \& DeGarmo, 2021). For caregivers involved with child welfare, simply learning the tenants of positive parenting may not be sufficient to overcome the negative responses that are triggered by the physiological state induced simply by interacting with their child. Parenting practices that are neutral, or even rewarding to most caregivers may be experienced as uniquely taxing. Meta-analyses have documented that brief psychoeducational approaches are generally insufficient to ameliorate risk of CM among caregivers who have already begun to abuse or neglect their children (e.g., Barth, 2009; Euser et al., 2015; Skowron \& Reinneman, 2005). We theorize that interventions that successfully reduce CM risk in these families need to (a) decouple maladaptive linkages between caregivers' physiological and behavioral responding, and (b) re-tune physiological responses to interrupt the coercive cycle and support prosocial caregiving (Skowron, 2015).

\section{Novel Mechanisms of Change in PCIT: Social Regulation Supports Parenting}

We theorize that PCIT effectively targets neural, physiological, and behavioral mechanisms of selfregulation and social cognition in caregivers in unique ways to support the development of more effective, positive parenting skills (see Figure 1). The keys to PCIT's effectiveness in lowering CM risk in families engaged with child welfare lie in its unique session format and the use of specific therapist techniques or approaches. 
PCIT employs a direct coaching model in which the PCIT therapist observes remotely and provides immediate feedback, support, and guidance through earbuds while the caregiver interacts with the young child. We contend that PCIT therapists function as crucial sources of real-time regulatory support that scaffold caregivers in-the-moment to lower their stress reactivity as they learn and practice new skills with their child. Therapists gently block harsh, aversive parenting behaviors that arise in the moment, and help caregivers to generate new alternative positive parenting responses to their child all in real-time. In this regard, we think that PCIT is essentially providing caregivers with inhibitory control training while they are in the act of parenting, and thus strengthening their emotion regulation and self-control skills while gains in positive parenting are achieved. In addition to providing regulatory scaffolding for parents throughout the course of treatment, we theorize that PCIT's live-coaching approach softens caregivers' threat-sensitive perceptions of their children, alters attributions of their children as threatening or overwhelming, and enables them to experience parenting as more rewarding. Together, these new experiences help parents to view their children in warmer, more affectionate, and developmentally appropriate ways that support lasting behavior change.

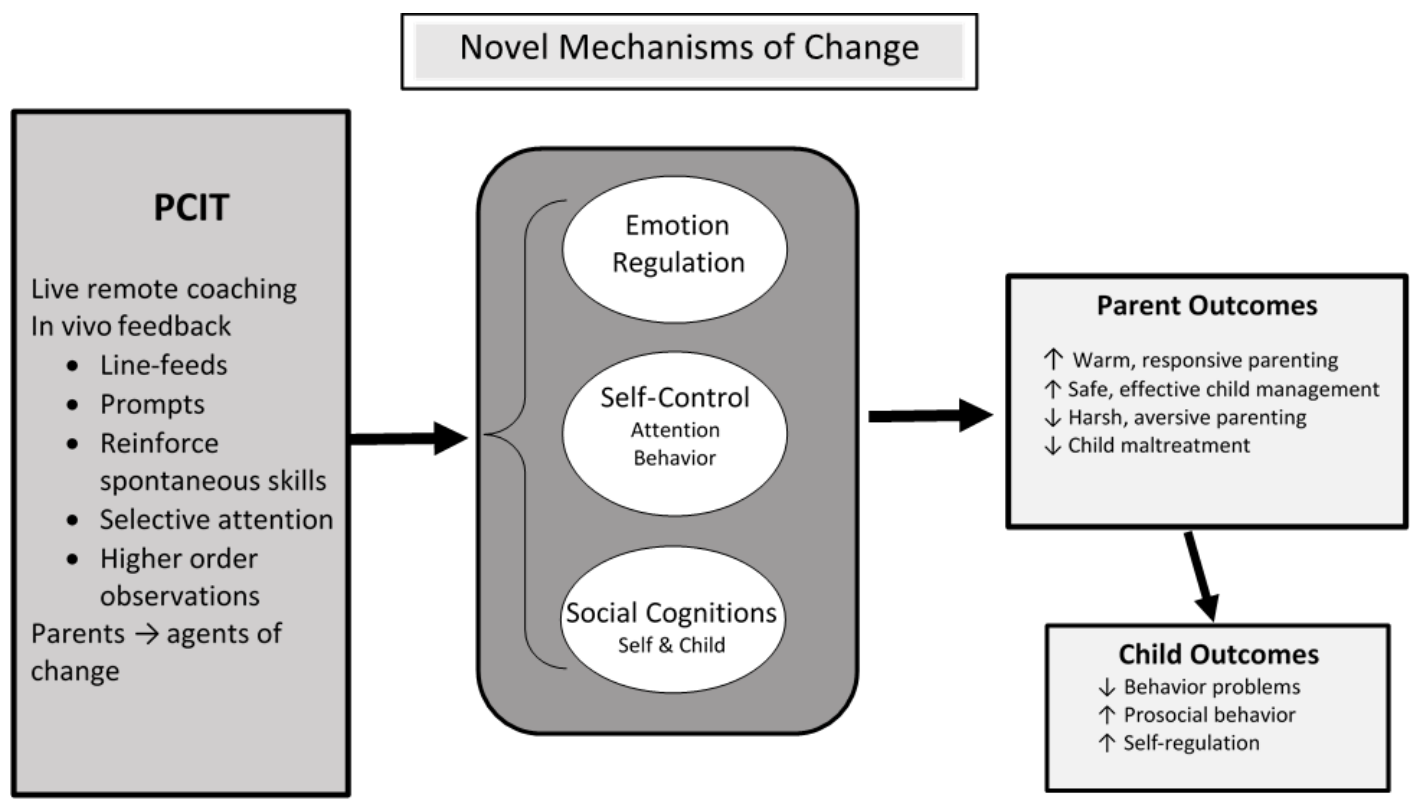

Figure 1. PCIT Intervention effects parent neural function, self-regulation, social cognitions, parenting, and child outcomes 
In sum, we think that PCIT facilitates new experiences and new understandings for parents that serve to strengthen their self-regulation skills and alter maladaptive social cognitions - two key drivers of problem parenting. Further, we propose that PCIT effectively targets neural, physiological, and behavioral mechanisms of self-regulation and social cognition in caregivers through its use of in vivo, parent coaching. This novel conceptual framework is informed by a growing literature on the social neurobiology of CM perpetration (e.g., Fisher \& Skowron, 2017; Kim, Strathearn, \& Swain, 2017; Rutherford \& Mayes, 2017; Skowron et al., 2013) and CM effects on children's development (Anda et al., 2006; DeBellis 2005; Lavi, Katz, Ozer, \& Gross, 2019; Teicher, Samson, Anderson, \& Ohashi, 2016). In the sections that follow, we describe PCIT and its implementation with families involved with child welfare. We elaborate on our conceptual framework that describes the mechanisms of change in PCIT and conclude with a discussion of the specific therapist techniques and session structure(s) used in PCIT that support reductions in harsh parenting and risk for CM in child welfare-involved families, and in particular, among families where child abuse and neglect has already begun.

\section{Parent-Child Interaction Therapy for Child Maltreatment Prevention}

$\mathrm{PCIT}$ is an intensive, behavioral parent training intervention that is grounded in social learning theory, and attachment and family systems theories. PCIT employs a live-skills coaching approach to re-structure parent-child interactions. Originally developed for treating externalizing, oppositional problems in children (Funderburk \& Eyberg, 2010; Zisser \& Eyberg, 2010) and adapted for use with child welfare families (e.g., Herschell \& McNeil, 2005), PCIT is one of a suite of effective, evidence-based behavioral parent training programs delivered in person and via internet-based, telehealth modalities (e.g., Comer et al., 2017; Gurwitch et al., 2020). Like other two-phase evidence-based parent training models, the parenting concepts taught in PCIT draw on Baumrind's theoretical construct of authoritative parenting. This construct has demonstrated that the combination of high warmth/acceptance and high demandingness/ structure in parenting is associated with positive social-emotional development in children (Larzelere, Morris, \& Harris, 2013). The relatively large and lasting effect sizes that PCIT achieves in CM-risk reduction relative to other programs with similar content may 
be attributed to the live coaching model, along with the well-established benefits of practicing skills with one's own child (Kaminski, Valle, Filene, \& Boyle, 2008). PCIT for CM families is designed to interrupt patterns of harsh, coercive interaction and enhance caregivers' positive, responsive parenting, child autonomy-support, and safe, effective child management skills.

CW-involved caregivers need help with basic parenting skills, and PCIT provides this very directly. Immediate live feedback from PCIT therapists through a wireless earpiece provides them with real-time coaching and support in-the-moment as they practice new parenting skills in sessions with their child. In this way, the live coaching to support parent skill-building creates opportunities in the moment for caregivers to adjust their behavior and correct errors on the spot. Immediate encouragement and feedback from the coach supports the parent in attempting new responses (e.g., ignoring throwing toys and praising gentle play) until the child's responses to the parent (e.g., increased appropriate play and physical/verbal affection) emerge to sustain the new way of interacting.

PCIT--Child Directed Interaction. The first phase of PCIT, Child Directed Interaction (CDI), roughly parallels the warmth and responsiveness dimension seen in an authoritative parenting style. In CDI, parents learn to follow their child's lead in the play, to strengthen their warm relationship with their child, and to refrain from harsh, aversive parenting and other actions that control the direction of the play (Eyberg \& Funderburk, 2011). Caregivers receive one didactic "CDI Teach" session in which the therapist teaches through instruction and role-plays to use a set of PRIDE "Do" skills (i.e., labelled Praise, Reflection, Imitation, Description, Enjoyment) during "special time" play with their child; to ignore minor child misbehavior; and to avoid use of "Don't" skills (i.e., criticism, sarcasm, commands, and questions). During the subsequent coaching sessions, parents wear a small earpiece while the therapist coaches them in real-time using a headset from an adjacent room with a one-way mirror or video monitor. PCIT is assessment-driven, using weekly reports about child behavior problems and conducting observations of parent-child transactions each session to inform the focus of coaching sessions. CDI is assigned as daily practice throughout treatment and is coached in every session. While 
PCIT therapists remain very active in session, i.e., facilitating gains in the positive parenting skills (e.g., Shanley \& Niec, 2010), they become less directive over time (Eyberg \& Funderburk, 2011). The PCIT coaching focus transitions from teaching CDI skills to helping caregivers recognize, appreciate, and understand the effects of the skills on their child, themselves, and their relationship. After families achieve CDI skills criteria (if in timeunlimited PCIT) or reach a set number of sessions (in a fixed-length version of PCIT), they transition into the second and final phase of PCIT. ${ }^{1}$

PCIT--Parent-Directed Interaction (PDI). Once CDI skills criteria are achieved, the work transitions from the $\mathrm{CDI}$, or relationship enhancement phase, into the PDI, or limit-setting phase of treatment that overlays gains achieved in CDI. The PDI phase of PCIT targets the demand dimension of Baumrind's authoritative parenting style, in which the caregiver learns to set developmentally appropriate expectations for the child's behavior in a context of warmth and support (Eyberg, Nelson, \& Boggs, 2008). The PDI phase begins with a Teach session focused on learning and role-playing safe, effective child management skills. Caregivers practice delivering effective developmentally-tailored commands one at a time, and following-through with specific praise for child compliance or a brief time-out from reinforcement for noncompliance. The caregiver learns a set discipline sequence which begins with a clear specific instruction to the child and follows with contingent praise for compliance or progression through a structured discipline sequence that moves from a specifically worded warning to a brief (3-minute) timeout from attention for noncompliance. Time-out from positive reinforcement is a very effective behavior management technique when implemented correctly (e.g., Dadds \& Tully, 2019), one that gives the maltreating caregiver alternatives to their habitual more harsh or erratic discipline techniques. Children are introduced to this new focus of treatment with an explanation that they will practice "minding and

\footnotetext{
${ }^{1}$ Most randomized controlled trials of PCIT with child welfare-involved families employ a fixed session PCIT format in which a specified number of sessions are provided in each treatment phase, rather than a true mastery model, in which treatment continues until the caregiver achieves set criteria. Substantial evidence indicates that significant treatment effects are achieved in fixed session PCIT among child welfare-involved families (e.g., Chaffin et al., 2004, 2011; Thomas \& ZimmerGembeck, 2011).
} 
listening," that is, doing what their caregiver says, and a demonstration to ensure the child understands.

Subsequent PDI coaching sessions advance from practicing very simple commands that demand less from the child (i.e., Please hand me a crayon from the box) to gradually more challenging "real life" commands that mimic real-world situations such as sharing, cleaning up, and transitions to non-preferred activities. Caregivers are coached to give clear, direct commands, follow through with each command given, then transition back into use of the CDI skills learned in the first phase of PCIT.

In initial PDI sessions the coach is highly active and directive in teaching the discipline protocol, ideally in an error-free learning experience for the child. Caregivers are guided to refrain from critical or harsh responses, or alternatively, from "giving up" on their ability to follow through with consistent discipline. The therapist is highly directive in the initial PDI coaching session - choosing the timing and words of commands and having the caregiver follow instructions rotely, returning briefly to CDI skills between command sequences. Through practicing time-out sequences correctly with heavy support from the therapist, the caregivers learn to be consistent, predictable, and calm as they implement PDI with their child. As the caregiver's skills develop, the therapist gradually loosens the reins, allowing the caregiver to begin to phrase effective commands, but quickly stepping in to correct if they falter in correct application of the PDI skills.

Therapist Coaching Techniques in PCIT. PCIT's live-coaching of skills practice during parent and child play uses a host of coaching techniques on a continuum from more to less active and directive in order to interrupt harsh control parenting and open up new ways for caregivers to respond positively and constructively. During live coaching of parents and their children in sessions, PCIT therapists make coaching statements that are generally brief, optimally just a few words, and offered in a nested rhythm within the parent-child interaction where the caregiver responds to the child, and the coach responds to the caregiver without disturbing the ongoing parent-child interaction (Funderburk, Gurwitch, Shanley, Chase, Nelson, Bard, \& McCoy, 2017; Kurtz, Funderburk, Bard, \& Gibson, 2019). For example, the child is building with blocks as the parent watches quietly, and the coach observes "She's working so patiently." The parent says "You are working so hard on that house," 
and the coach follows with "Nice labeled praise, Mom." Skills criteria for the CDI phase of treatment requires the caregiver give a minimum of 30 specified positive parenting skills in a 5-minute observation (or approximately one statement every 10 seconds) and the PCIT therapist utilizes roughly the same pace to provide immediate responsive feedback. Coaching should meet the parent at their level of skill, based on the brief behavioral observation and coding assessment conducted at the start of every PCIT session. If the parent is at a loss - either sitting silently or talking actively but using many "Don't" skills, the therapist will gently but firmly interrupt and offer direct line-feeds, where they tell the parent exact words to say. Therapists selectively block parent use of negative, aversive behaviors, by stepping in to suggest positive alternatives from among the PRIDE skills for use instead. For example, when the parent starts to correct the child ("It doesn't go that way"), the therapist might coach ("It's her game so anyway is fine. We'll just watch.")

PCIT therapists are trained to provide only the level of support needed to scaffold the caregiver to the next level of skills, selectively reinforcing specific parenting behaviors over others, prompting use of novel skills, and praising spontaneously-generated parent CDI skills. The therapist provides scaffolding for the caregiver's developing skills, providing more direct support (e.g. line feeding or prompting the parent to use a PRIDE skill) when the parent's skills are low. For example, a child is playing with pretend food and the parent is asking lots of questions. When the therapist prompts the parent ("Just say what he's doing") and the parent responds with another question, the therapist will gently line-feed a behavior description (e.g., Say "You are cooking breakfast"). When the parent repeats the behavior description to their child: "You are cooking breakfast," the therapist will follow with a labelled praise to the parent (e.g., "Great job describing his behavior!"). Therapists shift to provide less directive guidance over time as the parent's skills progress, for example, by praising spontaneously generated PRIDE skills (e.g., "Great idea to praise him for taking turns."). The therapist is alert for any spontaneous use of PRIDE skills by the parent, and quickly reinforces their independent production of the targeted skills. Immediate praise for correctly applied skills is a powerful responsive coaching technique that 
PCIT therapists employ to help caregivers develop skills (e.g., Barnett, Niec, Peer, Jent, Weinstein et al., 2017; Kurtz et al., 2019).

Over time as caregivers become increasingly skilled at generating the positive parenting (PRIDE) skills in session, PCIT therapists "back out of the parent's way," becoming less and less directive during live coaching in sessions, while continuing to reinforce caregivers' spontaneous skill use. In other words, the therapist steers the parent-child dyad toward a positive interaction, handing over the reins as caregivers grow in ability to sustain positive interaction. In a synchronous manner, the PCIT therapist engages flexibly with them, yielding control to the parent when the play is going well, and stepping in to help course-correct when the parent-child interaction hits a snag. This tight coordination that develops in the real-time exchanges between therapist and parent in session scaffolds the growing positive interactive synchrony that emerges between caregiver and child as treatment progresses. Caregivers grow increasingly able to sustain a warm, nurturing relationship with their child, and capable of supporting their child's autonomy when the child's behavior is socially appropriate, and gently re-directing the play when things go awry.

PCIT therapists also employ a form of feedback termed 'Higher Order' coaching statements that underscore the purpose and impact of PCIT skills. Higher order statements are intended to (a) support caregiver motivation to trust in and master the skills and (b) facilitate reappraisal by tying the specific parenting skills to desired treatment outcomes. For example, a statement linking the caregiver's praise to their child for taking turns (skill) to a positive outcome (i.e., the child will have more friends at school) is an example of a higher order statement. Higher order coaching often references the theory underlying PCIT with the intention of helping caregivers see the impact of their skills on the child and the parent-child relationship ("When you ignored his throwing the toys, he stopped"). Higher order statements include developmentally grounded observations that provide new, alternative frameworks through which caregivers can view their child's behavior (e.g., "He's sharing more because you praised sharing"), their own parenting behavior (e.g., "Your behavior descriptions are helping her stay focused"), or the nature of the interaction between them (e.g., "He's moved closer to you 
because you are being so warm and interested"). As shown in these examples, PCIT therapists highlight the positive impact of new skills on their child's well-being, and on the increasing warmth and closeness between parent and child. In sum, higher order statements help caregivers modify their social cognitions, to soften their negative, threat-sensitive attributions of their children, and reappraise their children's motives and behavior in more benign, developmentally-informed ways, while also helping them see themselves as capable and nurturing caregivers toward their child.

\section{PCIT Provides In Vivo Social Regulation}

PCIT does much more for families involved in child welfare than merely help caregivers and children learn behavioral alternatives to harsh, coercive interaction. We think that the mechanisms through which PCIT supports a caregiver in developing sustainable positive parenting practices is in therapist live scaffolding of selfregulation skills and cognitive reappraisals. These gains help caregivers effectively navigate stressful parent-child situations that ordinarily would trigger an impulsive harsh or rejecting reaction toward their child. We propose that PCIT effectively lowers risk for CM recidivism in child welfare-involved families because therapist coaching techniques support changes in caregiver emotion regulation, self-control skills, and social cognitive processes in ways that reduce aversive parenting and help caregivers experience parenting as more rewarding.

In PCIT's unique coaching format, the immediate live feedback through an earpiece worn by the caregiver enables PCIT therapists to provide them with intensive social regulation that supports emotion regulation and self-control while they are in the act of practicing new parenting skills with their child. Thus PCIT therapists serve in an external regulator role for parents with a history of $\mathrm{CM}$ perpetration, helping to reduce their stress reactivity during in-session skills practice, redirecting their attention in thoughtful ways (i.e., what to attend to vs. what to ignore), coaching new parenting skills-use in vivo; and helping to modify their negative, threat-sensitive social cognitions through use of higher order coaching. PCIT is unique in providing caregivers real-time support and feedback from the therapist in-the-moment as they practice new skills with their child. 
Because therapist coaching occurs directly through the earpiece, and thus largely out of sight of participating children, children experience their caregivers as the agents of positive change.

As shown in Figure 1 above, we think that PCIT achieves significant, positive, and lasting changes in CW parenting because it alters key drivers of maladaptive parenting: poor self-control, emotion dysregulation, and threat-based social cognitions. PCIT's unique session format and structure provides caregivers with immediate access to therapist reinforcements for positive parenting during parent-child interactions and intensive, realtime support for parent emotional, cognitive, and behavioral regulation in session. The live skills practice between parent and child while receiving in vivo coaching functions to interrupt coercive cycles and create space for caregivers to introduce new positive CDI skills and safe, effective child management (i.e., PDI) skills with each child experiencing their caregiver, rather than the therapist, as the source of positive change in their family. Support from the PCIT therapist provides parents with essential 'regulatory capital' (e.g., Cohn, 2011; Skowron, 2015) that helps to lower their physiological arousal, better manage their thoughts, feelings, and behavior, and function more effectively in their role as parents.

PCIT therapists serve as an external source of regulation that helps a caregiver manage their stress response and engage emotion regulation to support skills practice in session. Often caregivers involved with child welfare may experience some child behaviors as threatening or triggering, in light of their own trauma histories. For example, while playing with his mother, a boy who had been placed in out-of-home care following a history of domestic violence, with ensuing court-ordered treatment, asked "When will I see my dad?" The mother visibly stiffened, stopped playing, and shook her head "No." The coach said "This is hard. But he's not trying to upset you. Children just need to know what's happening in order to feel safe. If you know when he'll see dad again, just say 'in this many days'." The parent did so and the coach responded with, "There, you gave him what he needed even though it's so hard for you to think about those visits. Well done. Now take a deep breath and go back to the play. We adults will talk more about this later." The PCIT therapist's social regulation of parent emotion helps to moderate the impact of a caregiver's perceptions of threat or emotional arousal on 
their parenting behaviors in the moment, creating favorable conditions for caregivers to manage their emotional reactions to child behaviors while they are in the act of parenting. Caregivers experience greater emotional calm as PCIT therapists gently but firmly block aversive, intrusive parenting, and line-feed positive alternatives as needed, while providing ample praise and support for caregivers each time they use the new PRIDE skills. Early $\mathrm{CDI}$ sessions often require heavier coaching from the therapist as the parent may not have a schema for a mutually enjoyable playtime with their child. Over the course of a coaching session, the child often moves closer to the parent or even into their lap or gives spontaneous expressions of affection. In this way, the skills prompted and initially sustained by the therapist's feedback shift over to being reinforced and sustained by mutual pleasure in the parent-child play.

Having the therapist available in-the-moment to face the challenges that arise helps caregivers to remain calm even when strong emotions crop up, which reduces their cognitive load and leaves them freer to try out new parenting skills. For example, a father with a diagnosis of PTSD following military deployment sought PCIT due to the child's aggression with other children. The father acknowledged that his "hair trigger" temper and impatience with his three young children were disruptive to his relationships with the children and with his wife. In his second PCIT coaching session, he was rolling cars with his son when the three-year-old banged his car roughly into the car in his father's hand. The father was quickly coached to remain silent and roll his own car on the floor, praising the child when he joined in calmer play. "I wanted to grab that car away from him," the father reported afterward. The therapist's presence in the moment supported the father to regulate his emotional response and to test out a new behavioral response of withholding negative attention to redirect his son's behavior. Instead, the father was supported in finding child behavior to reinforce with a specific, labelled praise. Moreover, the therapist's use of higher order observations in CDI helps to soften his perceptions of his child's motives and behaviors (e.g., the child is seeking out the parent's attention versus trying to aggravate them), which further helps a parent to remain calm, regulate their emotional reactions, and respond more positively to their child. In another example, the child became restless and disengaged from play with a 
farm set, tossing the toys and wandering around the room. The therapist noted that the child had played with that single toy for over 20 minutes, suggesting, "He's been focused so well until now. I think we are testing the limits of his attention span. I'll bring in a new toy." In this brief exchange, the therapist is providing an alternate explanation for the child's disruptive behavior, noting improvement in the child's ability to focus, imparting relevant knowledge about child development, and modeling problem solving. For caregivers, the presence of a supportive other in the PCIT therapist helps to diminish the negative affect felt in the moment and reduce realtime demands on self-regulatory resources (e.g., Coan, 2011; Coan, Schaefer, \& Davidson, 2006; Skowron, 2015), enabling caregivers to remain calm enough to implement the new skills (i.e., ignore minor child misbehavior and praise positive alternatives).

Over time, interactions between parent and child become more and more positive as parents get better at regulating their emotional responses and relating to their child, rather than perceiving them through a lens of negative emotionality. Parents are freed up to experience the rewarding aspects of interaction with their child and increasingly find their child more enjoyable. The ability to use selective attention and the PRIDE skills fosters a mutually enjoyable interaction in CDI, and the scaffolding of PDI skills allows the parent to follow a set of limitsetting skills in a way that is calm and predictable for both parent and child. We think that PCIT's live coaching in-the-moment effectively functions to decouple maladaptive physiology--behavior linkages and re-tune the caregivers physiological responses during parenting (e.g., Skowron et al., 2013). This in turn makes the experience of warm, responsive parenting positively reinforcing for these caregivers rather than triggering a harsh, controlling or rejecting response as may have been programmed into their physiology.

PCIT's live-coaching approach also helps to strengthen parent self-control skills, both in terms of helping caregivers become more thoughtful about what they pay attention to and how they behave while parenting their child. PCIT helps parents learn to be more selective about where and how to direct their attention to their child. CW-involved caregivers often tend to focus more on their child's problem behavior and miss their child's bids for attention and prosocial behavior (Peterson, Joseph, \& Feit, 2014). Through social regulation of 
attention, PCIT therapists help caregivers strengthen their attention focusing skills while interacting with their child; to become more intentional about what they pay attention to and what they choose to ignore. Through a variety of techniques, PCIT therapists help caregivers learn to pay more attention to child behavior that they want to see more of (i.e., catch good child behavior and reinforce it), and pay less attention to the kinds of child behaviors that they want to extinguish (i.e., ignoring minor child misbehavior). For example, a mother who presented for treatment due to concerns about her three-year-old's "obsession" with aggressive play realized in a single coaching session that she had been differentially attending to his aggressive play. The act of describing and praising her child's play when he acted out 'rescue' rather than 'destruction' led to a dramatic shift in his play, and led to the mother's re-appraisal of her son's "aggressive tendencies" through recognition of the power of her attention. The PCIT therapist's immediate feedback as the caregiver interacts with their child can lead to striking realignments of the parent-child interaction in a short time. Children delight in their caregivers' positive attention, providing caregivers with further reinforcement for the new parenting skills, and the exchanges build on one another as children become more pleasant and reinforcing interactive partners. Caregivers begin to experience interactions with their children as more rewarding. Because the therapist coaches from a distance, the young child experiences the parent as the agent of change, further strengthening the relatively rapid shift in the dynamics of the relationship.

Therapists' live coaching in PCIT sessions helps caregivers build their behavioral control skills during parent-child interactions. PCIT therapists selectively block aversive parenting behaviors, and scaffold caregivers to call forth more prosocial, developmentally sensitive, and responsive skills. Scaffolding skills implies meeting the caregiver at their level, perhaps initially feeding parents the exact words of a praise, then suggesting several possible child behaviors they could praise, moving to just prompting the parent to keep up the praise, and eventually mostly just noticing and reinforcing the parent's independent use of praise. By helping parents to inhibit 'maladaptive' behaviors in the moment they're set to occur, and instead engage positive, responsive skills (that are perhaps less familiar), PCIT therapists prevent escalating coercive interactions that are often habitual in 
families where child maltreatment occurs. For example, a child might wander to the door, placing a hand on the knob as if to leave the room. The caregivers' instinct is to issue a negative directive - "Don't you open that door." The therapist will coach the caregiver to ignore the mildly provocative behavior and instead engage in an interesting activity - "I'm going to open up this new toy," and coach the parent to provide immediate positive attention to the child when she approaches the new toy. When caregivers need help in session to resist the tendency to control or withdraw from their child, the PCIT therapist's live coaching in the moment helps caregivers to remain active in sessions and extend periods of sustained, positive interaction with their child. Over time, these experiences may help to 'reprogram' parent physiology to support and reinforce use of the new parenting skills (e.g., positive, responsive parenting; safe and effective child management). Given the research documenting harsh, controlling patterns of parenting and coercive cycles in CM families (e.g., Wilson et al., 2008), it may be especially stressful for parents to let their child take the lead while they're playing together in CDI. Yet opportunities for children to assert age-appropriate autonomy are important for healthy development (Grolnick \& Ryan, 1989; Ryan \& Deci, 2017; Vasquez, Patall, Fong, Corrigan, \& Pine, 2016). For example, a child might be trying to put a toy into a space that is too small. As the caregiver reaches for the toy saying, "Not that way," the therapist may intervene, "Just watch; he's figuring it out...There! You can praise him for sticking with it until he figured it out."

Alternatively, some caregivers (i.e., neglectful) are non-responsive and withdraw when feeling uncomfortable or stressed. PCIT therapists coach parents in CDI sessions to remain actively engaged with their child even when they are tired or feeling distracted. A coach might comment, "I know this repetitive play can be dull! She has rolled and cut out 10 play doh cookies in a row. You are being so patient! She is learning to persist and you are right there supporting her." At the end of the coaching session, it is often apparent to the parent (once pointed out by the therapist) that they feel invigorated and uplifted by the pleasant time spent with their child and finds the experience more rewarding. 
Therapists provide regulatory support to parents in PDI phase sessions as well, especially as parents learn to communicate directly and gain compliance in firm and prosocial ways. For example, initial PDI sessions with some CM-exposed children include resistance and defiance as the child tests the limits of the parent's new way of behaving. They often have deeply ingrained patterns of interaction such as having the parent withdraw an expectation if the child tantrums long enough or loud enough. The therapist must help the parent remain calm and "weather the storm" of testing without lashing out or giving in until the child develops trust that the parent will follow the new rules of clear expectations and predictable consequences. Just as CDI skills can be tailored to help an impulsive child to develop frustration tolerance, and help a passive child to develop confidence, coaches can direct coaching to the parent's style of emotion regulation. The therapist may have the parent take deep calming breaths if their temper starts to rise; PCIT therapists help parents resist lapses in selfcontrol (e.g., "You're not going to respond to that because you are the adult and you're staying calm even though he's testing your patience"). They will block a parent's tendency to issue rapid-fire commands, guiding them back to use of CDI skills in between discipline sequences. Alternatively, the therapist may need to reassure a parent who wants to give in (e.g., "We asked her to put one block on the house. Do you think she understands? Does it seem fair? Ok, then we are going to follow through and expect her to listen to you because she's little and she needs to know you can handle this situation."). The therapist often uses developmentally grounded, higher order observations to normalize the child behaviors as harmless (e.g., 'All three year olds ask "why, why, why,"') or even positive (e.g., "He is very clever at testing all the ways you--his parent--might respond-many children wouldn't have thought of that!"). PCIT helps parents to revise their attributions of their child as un-manageable and of themselves as incompetent or a victim of their difficult child.

The simple tasks practiced in early PDI sessions are intended to meet the child at a point of least resistance, emphasizing the notion of practicing how to follow the parent's directions, even for relatively unimportant tasks. As quickly as the parent and child master the basic structure - which can vary in time from a single session to several sessions - the therapist guides the parent to practice giving more realistic commands 
like straightening up the room at the end of the session or walking at the parent's side to exit the building. The steps of PDI offer a protocol of exact words to say in moving through the steps of limit setting. The parent can, in essence, follow a script (e.g., "You didn't do what I said, so now you have to sit in Timeout") which gives the child predictable limits, and relieves the parent of the pressure to "ad lib" in stressful situations that otherwise may devolve to negative attention and escalating coercive exchanges between parent and child (e.g., "Why don't you ever do what I tell you? You are being naughty. Do you need a spanking?"). As the parent's skills develop, the therapist gradually loosens the reins, allowing the parent to begin to phrase effective commands, but quickly stepping in to correct if the parent missteps in application of the PDI skills because it is important for the child's learning that demands are clear rather than confused or inconsistent. Parents begin to experience time with their child as more rewarding, which further reinforces parents' reliance on new skills, builds their confidence, and fuels further gains in positive parenting. These benefits simultaneously reduce their tendency to resort to harsh or withdrawn parenting practices and break down the coercive cycle.

In PDI the therapist helps the parent form a habit of offering their child a rationale before giving a direction (e.g., "I want to color a flower. Please give me the pink crayon."). Forming a habit of providing an explanation along with an instruction helps the parent learn to set fair expectations (e.g., "It's time for dinner. Please turn off your tablet"), rather than expecting blind obedience to abrupt commands (e.g., "Turn off your tablet now"), or giving a command and then explaining it -- which risks digressing into an escalating argument (e.g., Child: "But why can't I keep playing?" Parent: "It's almost time to eat." Child: "But I'm not hungry," etc.). Therapists guide the parent to return to positive PRIDE skills between requests for child compliance, so that following directions is not experienced as overly demanding or punishing. Having a predictable discipline structure that both the child and parent understand de-escalates behavior management exchanges by relieving the parent of in-the-moment decisions that are often clouded by emotional reactivity, and by letting the child trust in the parent's predictable mild, but consistent follow-through. They are both aided by a mutual "cooling off period" between demands that the previously mastered CDI skills provide. The parent experiences the joint 
success of feeling competent to manage routine parenting tasks and seeing their child follow developmentally appropriate expectations "just like all the other children."

Likewise, the child begins by learning to comply with their parent's simple direct requests (i.e., "Please put the nose on Mr. Potato Head.") and gradually progresses to complying with more challenging parent requests (e.g., sharing a favorite toy). The act of following directions becomes a routine, even pleasant, interaction in which demands for cooperation are interspersed with adult-supported child autonomy. The child's increasing cooperation is celebrated, and children often take great pride in their growing capacity for managing their own behavior and emotions. The child and parent both increase their sense of competence in their roles. Though PCIT's core focus is on teaching parenting skills, it seems that the calming that comes with more positive interactions allows space for CM parents to modify cognitive appraisals, replacing negative, threat-based perceptions about their children (e.g., "My child doesn't pay attention unless I spank him" and "He's out to get me!") and themselves (e.g., "I cannot manage this child"). PCIT therapists offer parents alternative interpretations for emotionally evocative stimuli that help to soften their negative attributions about their children and themselves. PCIT therapists' observations of children's behavior and parent-child interactions effectively help parents reframe their child's positive and negative behaviors and their own contributions to the caregiving relationship. Over time, these new ways of thinking increase caregivers' capacities to parent in more confident and benign ways, to experience and enjoy their child's positive responses to the new parenting skills, and to relax into the growing warmth in the parent-child relationship.

Therapists help caregivers re-appraise threat-based perceptions and see their children through a developmentally-informed lens. The parent who thought the child "is just supposed to behave" can begin to appreciate the child's positive behavior as worthy of attention and praise. The therapist can help make the connection between the parent's attention to prosocial behavior and the child's response (e.g., directing the parent to attend to the child's positive response to the parent, they may say, "You are teaching him to share! 
You praised sharing and now he's bringing you another toy! He loves your warm attention when he does something you like").

Therapists also help caregivers to reappraise negative child behavior by interpreting the child's behavior through a developmental lens and teaching the basic principles of social learning theory (i.e., behaviors you pay attention will increase and behavior you refrain from reinforcing will reduce or stop). For example, a mother was glancing at her phone during play and the child emptied a toy bucket onto the floor and placed the bucket on his head. The mother looked up in irritation, and the therapist noted, "He wants your attention back; he's trying to make you laugh"). For caregivers who hold harsh, threat-sensitive attributions of their child's intentions and behavior, feedback in the moment about typical child development and social learning principles can help them begin to revise their appraisal of the child. While some caregivers tend to be harsh or overly demanding, others tend to be passive and may worry that enforcing limits could be harmful to the child or to the parent-child relationship. Again, information about child development and social learning principles offered in the moment through coaching can help the parent realize that setting clear, developmentally appropriate expectations will help and not hurt their child. Caregivers learn to recognize and support their child's developing ability to regulate their behavior and manage tolerable amounts of stress involved in having to share a favorite toy or transition out of an enjoyable activity. For example, in a later PDI session, a mother directed her son to pick his coloring sheet off the floor. He angrily wadded up the paper and threw it on the table. The therapist had the mother praise the child for compliance and then give a new instruction to flatten out the paper that he had crumpled. As the child did so, the mother realized that she had it within her to help her child by setting expectations for age-appropriate behavior. He was not an uncontrollable child, but rather a child who was learning to develop self-control with his mother's support. These new understandings help soften a caregiver's critical, threat-sensitive attributions of their child and strengthen confidence in their parenting skills.

In summary, PCIT helps parents to reappraise themselves and their children over the course of treatment. Parents' perceptions soften and recalibrate, shaped by new, alternative, developmentally- informed 
ways of thinking about their child's intentions and behavior and shifting views of self as a parent. These changing social cognitions help parents feel more confident and effective as they are less "triggered" by the child or situation. Parents become better at perspective-taking, seeing their children as they are, enabling them to enjoy their children more, all of which further supports and sustains the changes that parents make in their parenting behaviors.

\section{Summary \& Future Directions}

Originally developed for treating externalizing, oppositional problems in children, PCIT is one of a suite of effective, evidence-based, behavioral parent training programs. In the last two decades, PCIT has been extended to treat caregivers and children involved in CW for physical child abuse and neglect, and has demonstrated long-term reductions in CM recidivism. PCIT is a two-phase treatment model that begins with a relationship enhancement phase (CDI), which addresses the relative deficits in positive interactions and the reliance on negative attention that characterizes many parent-child relationships in $\mathrm{CW}$-involved families. After strengthening the warmth in the relationship, PCIT moves on to the behavior management phase (PDI), in which parents and children learn a predictable discipline sequence that replaces the inconsistent, ineffective, and often harsh discipline practices that were in place prior to PCIT.

Further research is needed to shed new insights on the individual and family characteristics that predict which caregivers and children will experience the greatest gains from PCIT treatment. For example, Motivational Enhancement (ME) represents a research-supported adaptation to PCIT intended for parents who may be mandated into treatment or are otherwise resistant to the idea of changing their parenting behaviors. ME sessions are designed to clarify parents' goals for treatment, enhance motivation to acquire new parenting skills, and counter obstacles to engagement, such as competing beliefs about optimal child-rearing, conflicts with the child welfare system, and myriad other stressors that may block new skills acquisition and retention in treatment. Greater readiness for change is associated with greater likelihood of completing PCIT among families involved with child welfare services (Skoranski et al., 2021), and predicts maintenance of post-treatment 
reductions in $\mathrm{CM}$ reports (Chaffin et. al, 2011). These findings and others suggest that increased attention to understanding predictors of intervention response is important to inform effective approaches for increasing the impact and reach PCIT and other effective, behavioral parent training programs.

Among two-phase behavioral parent training programs, PCIT demonstrates relatively large effect sizes among families involved with child welfare, which we attribute to the live remote coaching format in which the therapist gives immediate feedback to the parent as they interact with their child, teaching new skills and disrupting unhelpful habitual patterns in the moments they occur. Parents with histories of perpetrating CM struggle to maintain positive engagement with their child during moments of emotional arousal. Their physiological reactions to interactions that might set the stage for warmth and support in some parents, but can trigger harsh or rejecting behavior from parents at risk for perpetrating $\mathrm{CM}$. We contend that the guided, successful parenting interchanges experienced in PCIT coaching sessions lower caregivers' stress reactivity and de-couple maladaptive physiology-behavior linkages, in effect reprogramming physiology in the context of parenting. In sum, we believe that PCIT helps alter three drivers of CM parenting: Deficits in self-control, emotion dysregulation, and threat-based social cognitions about one's self and one's child.

We are evaluating the validity of this conceptual model of PCIT effectiveness for CM prevention using a randomized clinical trial (Nekkanti et al., 2020) grounded in a translational social neuroscience framework for assessing outcomes (e.g., Fisher \& Skowron, 2017). As findings emerge from the outcome studies of PCIT with child welfare-involved families, further research is needed to understand the impact of PCIT on the neural architecture of the parent brain that underscores stress reactivity and regulatory control in the context of parenting. Prevention of $\mathrm{CM}$ is a high priority and $\mathrm{PCIT}$ is both an effective and cost-effective intervention. In presenting this conceptual model of PCIT's in vivo social regulation of parenting, we hope to encourage others to investigate and further explore the ideas shared here. 


\section{References}

Anda, R. F., Felitti, V. J., Bremner, J. D., Walker, J. D., Whitfield, C., Perry, B. D., Dube, S. R., \& Giles, W. H. (2006). The enduring effects of abuse and related adverse experiences in childhood. A convergence of evidence from neurobiology and epidemiology. European archives of psychiatry and clinical neuroscience, 256, 174-186. doi.org/10.1007/s00406-005-0624-4

Aos, S., Lee, S., Drake, E., Pennucci, A., Klima, T., Miller, M., Anderson, L., Mayfield, J., \& Burley, M. (2011). Return on investment: Evidence-based options to improve statewide outcomes (Document No. 11-071201). Olympia: Washington State Institute for Public Policy.

Assink, M., Spruit, A., Schuts, M., Lindauer, R., van der Put, C.E., \& Stams, G.J.M. (2018). The intergenerational transmission of child maltreatment: A three-level meta-analysis. Child Abuse \& Neglect, 84, 131-145. doi.org/10.1016/j.chiabu.2018.07.037

Barnett, M. L., Niec, L. N., Peer, S. O., Jent, J. F., Weinstein, A., Gisbert, P., \& Simpson, G. (2017). Successful Therapist-Parent Coaching: How In Vivo Feedback Relates to Parent Engagement in Parent-Child Interaction Therapy. Journal of Clinical Child and Adolescent Psychology, 46, 895-902.

\section{https://doi.org/10.1080/15374416.2015.1063428}

Barth R. P. (2009). Preventing child abuse and neglect with parent training: evidence and opportunities. The Future of children, 19(2), 95-118. https://doi.org/10.1353/foc.0.0031

Belsky, J. (1993). Etiology of child maltreatment: A developmental-ecological analysis. Psychological Bulletin, 114(3), 413-434. https://doi.org/10.1037/0033-2909.114.3.413

Belsky, J., Conger, R., \& Capaldi, D. M. (2009). The intergenerational transmission of parenting: Introduction to the special section. Developmental Psychology, 45(5), 1201-1204. doi:10.1037/a0016245

Brown, J., Cohen, P., Johnson, J.G., \& Salzinger, S. (1998). A longitudinal analysis of risk factors for child maltreatment: Findings of a 17-year prospective study of officially recorded and self-reported child abuse and neglect. Child Abuse \& Neglect, 22, 1065-1078. 
Bugental, D. (2009). Predicting and preventing child maltreatment: A biocognitive transactional approach. In A. Sameroff (Ed.), The transactional model of development: How children and contexts shape each other (p. 97-115). American Psychological Association. https://doi.org/10.1037/11877-006

Bugental, D. B., Blue, J., Cortez, V., Fleck, K., Kopeikin, H., Lewis, J. C., \& Lyon, J. (1993). Social cognitions as organizers of autonomic and affective responses to social challenge. Journal of Personality and Social Psychology, 64, 94-103. https://doi.org/10.1037/0022-3514.64.1.94

Burgess, R., \& Conger, R. (1978). Family Interaction in Abusive, Neglectful, and Normal Families. Child Development, 49(4), 1163-1173. doi:10.2307/1128756

Chaffin, M., Funderburk, B., Bard, D., Valle, L. A., \& Gurwitch, R. (2011). A combined motivation and parent-child interaction therapy package reduces child welfare recidivism in a randomized dismantling field trial. Journal of Consulting and Clinical Psychology, 79, 84-95.

Chaffin, M., Silovsky, J. F., Funderburk, B., Valle, L. A., Brestan, E. V., Balachova, T., . . \& Bonner, B. L. (2004). Parent-child interaction therapy with physically abusive parents: Efficacy for reducing future abuse reports. Journal of Consulting and Clinical Psychology, 72, 500-510.

Cicchetti, D., \& Toth, S. L. (2005). Child maltreatment. Annual Review of Clinical Psychology, 1, 409-438.

Coan, J. A. (2011). The Social Regulation of Emotion. In J. Decety \& J.T. Cacioppo (Eds.), Oxford Handbook of Social Neuroscience (pp. 614-623). New York: Oxford University Press. DOI:

10.1093/oxfordhb/9780195342161.013.0041

Coan, J. A., Schaefer, H. S., \& Davidson, R. J. (2006). Lending a Hand: Social Regulation of the Neural Response to Threat. Psychological Science, 17(12), 1032-1039. https://doi.org/10.1111/i.1467-9280.2006.01832.x

Comer, J. S., Furr, J. M., Miguel, E. M., Cooper-Vince, C. E., Carpenter, A. L., Elkins, R. M., Kerns, C. E., Cornacchio, D., Chou, T., Coxe, S., DeSerisy, M., Sanchez, A. L., Golik, A., Martin, J., Myers, K. M., \& Chase, R. (2017). Remotely delivering real-time parent training to the home: An initial randomized trial of Internet- 
delivered parent-child interaction therapy (I-PCIT). Journal of Consulting and Clinical Psychology, 85(9), 909-917. https://doi.org/10.1037/ccp0000230

Dadds, M. R., \& Tully, L. A. (2019). What is it to discipline a child: What should it be? A reanalysis of time-out from the perspective of child mental health, attachment, and trauma. American Psychologist, 74(7), 794808. http://dx.doi.org/10.1037/amp0000449

DeBellis, M. D. (2005). The psychobiology of neglect. (2005). Child Maltreatment, 10, 150-172.

Denham, S. A., Workman, E., Cole, P. M., Weissbrod, C., Kendziora, K. T., \& Zahn-Waxler, C. (2000). Prediction of externalizing behavior problems from early to middle childhood: the role of parental socialization and emotion expression. Development and Psychopathology, 12(1), 23-45. https://doi.org/10.1017/s0954579400001024

Euser, S., Alink, L.R., Stoltenborgh, M., Bakermans-Kranenburg, M.J., \& van IJzendoorn, M.H., (2015). A gloomy picture: a meta-analysis of randomized controlled trials reveals disappointing effectiveness of programs aiming at preventing child maltreatment. BMC Public Health 15, 1068. https://doi.org/10.1186/s12889$\underline{015-2387-9}$

Eyberg S. M., \& Funderburk B. (2011). Parent-child interaction therapy protocol. Gainesville, FL: PCIT International.

Eyberg, S.M., Nelson, M. M., \& Boggs, S.R. (2008). Evidence-based treatments for child and adolescent disruptive behavior disorders. Journal of Clinical Child and Adolescent Psychology, 37, 213-235. doi/abs/10.1080/15374410701820117

Fisher, P. A., \& Skowron, E. A. (2017). Social-learning parenting intervention research in the era of translational neuroscience. Current opinion in psychology, 15, 168-173. https://doi.org/10.1016/i.copsyc.2017.02.017

Funderburk, B.W., \& Eyberg S.M. (2010). Parent-Child Interaction Therapy. In: J.C. Norcross, G.R. VandenBos, \& D.K. Freedheim (Eds), History of Psychotherapy: Continuity and Change. 2nd ed, (pp. 415-420). Washington, DC: American Psychological Association. 
Funderburk, B., Gurwitch, R., Shanley, J., Chase, R., Nelson, M., Bard, E., \& McCoy, C., (2017). COACH System Manual; CDI Observational Assessment of Coaching Highlights. Unpublished manuscript.

Granic, I., \& Patterson, G. R. (2006). Toward a comprehensive model of antisocial development: A dynamic systems approach. Psychological Review, 113(1), 101-131. https://doi.org/10.1037/0033-

\section{$\underline{\text { 295X.113.1.101 }}$}

Grolnick, W. S., Ryan, R. M. (1989). Parent styles associated with children's self-regulation and competence in school. Journal of Educational Psychology, 81, 143-154.

Gunnar, M. R., Fisher, P. A., \& The Early Experience, Stress, and Prevention Network (2006). Bringing basic research on early experience and stress neurobiology to bear on preventive interventions for neglected and maltreated children. Development and Psychopathology, 18, 651-677.

Gurwitch, R. H., Salem, H., Nelson, M. M., \& Comer, J. S. (2020). Leveraging parent-child interaction therapy and telehealth capacities to address the unique needs of young children during the COVID-19 public health crisis. Psychological Trauma: Theory, Research, Practice, and Policy, 12(S1), S82-S84. http://dx.doi.org/10.1037/tra0000863

Hakman, M., Chaffin, M., Funderburk, B., \& Silovsky, J.F. (2009). Change trajectories for parent-child interaction sequences during parent-child interaction therapy for physical child abuse. Child Abuse \& Neglect, 33, 461-470. https://doi.org/10.1016/j.chiabu.2008.08.003

Herschell, A., \& McNeil, C. (2005). Theoretical and empirical underpinnings of parent-child interaction therapy with child physical abuse populations. Education and Treatment of Children, 28(2), 142-162.

Joosen, K. J., Mesman, J., Bakermans-Kranenburg, M. J., \& van IJzendoorn, M. H. (2013). Maternal overreactive sympathetic nervous system responses to repeated infant crying predicts risk for impulsive harsh discipline of infants. Child Maltreatment, 18(4), 252-263. https://doi.org/10.1177/1077559513494762 
Kaminski, J., \& Claussen, A. (2017). Evidence base update for psychosocial treatments for disruptive behaviors in children. Journal of Clinical Child and Adolescent Psychology, 46(4), 477-499. doi:10.1080/15374416.2017.1310044.

Kaufman Best Practices Project. (2004). Kaufman Best Practices Project Final Report: Closing the Quality Chasm in Child Abuse Treatment; Identifying and Disseminating Best Practices. Retrieved Dec. 4, 2020.

Kaufman, J., \& Zigler, E. F. (1989). The intergenerational transmission of child abuse. In D. Cicchetti \& V. Carlson (Eds.), Child maltreatment: Theory and research on the causes and consequences of child abuse and neglect (p. 129-150). Cambridge University Press. https://doi.org/10.1017/CBO9780511665707.006

Kennedy, S.C., Kim, J.S., Tripodi, S.J., Brown, S.M., \& Gowdy, G. (2014). Does Parent-Child Interaction Therapy reduce future physical abuse? A meta-analysis. Journal of Social Work Practice, 26, 147-156. doi.org/10.1177/1049731514543024

Khoury, J. E., Rajamani, M., Bureau, J.-F., Easterbrooks, M. A., \& Lyons-Ruth, K. (2020). Aspects of Parent-Child Interaction from Infancy to Late Adolescence are Associated with Severity of Childhood Maltreatment through Age 18. International Journal of Environmental Research and Public Health, 17(11), 3749. MDPI AG. doi.org/10.3390/ijerph17113749

Kim, P., Strathearn, L., \& Swain, J.E., (2017). The maternal brain and its plasticity in humans. Hormones \& Behavior, 77, 113-123. doi:10.1016/j.yhbeh.2015.08.001.

Kurtz, S., Funderburk, B., Bard, E., \& Gibson, K., (August, 2019). Using COACH Coding to Enhance Your PCIT Practice. Symposium presented at the 2019 PCIT International Biennial Convention, Chicago, IL. Larzelere, R.E., Morris, A.S., \& Harrist, A.W. (2013). Authoritative parenting: Synthesizing nurturance and discipline for optimal child development. American Psychological Association: Washington, D.C. Lavi, I., Katz, L., Ozer, E., \& Gross, J. (2019). Emotion Reactivity and Regulation in Maltreated Children: A MetaAnalysis. Child Development, 90, 1503-1524. doi:https://doi.org/10.1111/cdev.13272. 
Lee, S., Aos, S., Drake, E., Pennucci, A., Miller, M., \& Anderson, L. (2012). Return on investment: Evidence-based options to improve statewide outcomes, April 2012 (Document No. 12-04-1201). Olympia: Washington State Institute for Public Policy.

Lieneman, C, Girard, E.I., Quetsch, L.B., McNeil, C.B., (2020). Emotion regulation and attrition in Parent-Child Interaction Therapy. Journal of Child \& Family Studies, 29, 978-996. https://doi.org/10.1007/s10826019-01674-4

Martorell, G. A., \& Bugental, D. B. (2006). Maternal variations in stress reactivity: Implications for harsh parenting practices with very young children. Journal of Family Psychology, 20(4), 641-647. https://doi.org/10.1037/0893-3200.20.4.641

McCanne, T. R., \& Hagstrom, A. H. (1996). Physiological hyperreactivity to stressors in physical child abusers and individuals at risk for being physically abusive. Aggression and Violent Behavior, 1, 345-358.

Nekkanti, A., K., Jeffries, R., Scholtes, C., M., Shimomaeda, L., DeBow, K., Wells, J., N., Lyons, E.R., Giuliano, R., Gutierrez, F., Woodlee, K.X., Funderburk, B., \& Skowron, E.A. (2020). Study Protocol: The Coaching Alternative Parenting Strategies (CAPS) Study of Parent-Child Interaction Therapy in Child Welfare Families. Frontiers in Psychiatry, 9(02). doi:10.3389/fpsyt.2020.00839.

Pidgeon, A., \& Sanders, M.R. (2009). Attributions, parental anger and risk of maltreatment. International Journal of Child Health and Human Development, 2, 57-69.

Rogosch, F. A., Cicchetti, D., \& Aber, J. L. (1995). The role of child maltreatment in early deviations in cognitive and affective processing abilities and later peer relationship problems. Development and Psychopathology, 7, 591-609.

Rogosch, F. A., Cicchetti, D., Shields, A., \& Toth, S. L. (1995). Parenting dysfunction in child maltreatment. In M. H. Bornstein (Ed.), Handbook of parenting, Vol. 4. Applied and practical parenting (p. 127-159). Lawrence Erlbaum Associates, Inc. 
Rutherford, H.J.V., \& Mayes, L.C., (2017). Parenting and addiction: Neurobiological insights. Current Opinion in Psychology, 15, 55-60. doi.org/10.1016/j.copsyc.2017.02.014

Rutherford, H.J.V., Williams, S.K., Moy, S., Mayes, L.C., \& Johns, J.M. (2011). Disruption of maternal parenting circuitry by addictive process: rewiring of reward and stress systems. Frontiers in Psychiatry, 2, 37.

Ryan, R. M. \& Deci, E. L. (2017). Self-determination theory: Basic psychological needs in motivation, development, and wellness. New York, NY: Guilford Publishing.

Shackman, J. E., Shackman, A. J., \& Pollak, S. D. (2007). Physical abuse amplifies attention to threat and increases anxiety in children. Emotion, 7, 838-852. doi=10.1037/1528-3542.7.4.838.

Shanley, J.R., \& Niec, L.N. (2010). Coaching parents to change: The impact of in vivo feedback on parents' acquisition of skills. Journal of Clinical Child \& Adolescent Psychology, 39, 282-287. DOI: $\underline{10.1080 / 15374410903532627}$

Skoranski, A., Skowron, E., Nekkanti, A., Scholtes, C., Lyons, E., \& DeGarmo, D. (2021). PCIT engagement and persistence among child welfare-involved families: Associations with harsh parenting, physiological reactivity, and social cognitive processes at intake. Development and Psychopathology, 1-18. DOI: $\underline{10.1017 / \mathrm{S} 0954579421000031}$

Skowron, E.A. (2015). Understanding autonomic physiology and relationship processes in high-risk families. In R. Noone \& D. Papero (Eds.), The Family Emotional System: An Integrative Concept for Theory, Science, and Practice (pp. 237-256). Rowman \& Littlefield. ISBN-13: 978-0739198957

Skowron, E. A., \& Reinemann, D. H. S. (2005). Psychological interventions for child maltreatment: A metaanalysis. Psychotherapy: Theory, Research, Practice, and Training, 42, 52-71.

Skowron, E. A., \& Woehrle, P. (2012). Child maltreatment. In N. A. Fouad, J. A. Carter, \& L. M. Subich (Eds.), APA handbook of counseling psychology, Vol. 2. Practice, interventions, and applications (p. 153-180). American Psychological Association. https://doi.org/10.1037/13755-007 
Skowron, E. A., Kozlowski, J. M., \& Pincus, A. L. (2010). Differentiation, self-other representations, and rupturerepair processes: Predicting child maltreatment risk. Journal of Counseling Psychology, 57(3), 304-316. https://doi.org/10.1037/a0020030

Skowron, E. A., Cipriano-Essel, E., Benjamin, L. S., Pincus, A. L., \& Van Ryzin, M. J. (2013). Cardiac Vagal Tone and Quality of Parenting Show Concurrent and Time-Ordered Associations That Diverge in Abusive, Neglectful, and Non-Maltreating Mothers. Couple \& family psychology, 2(2), 95-115. https://doi.org/10.1037/cfp0000005

Skowron, E. A., Cipriano-Essel, E. A., Gatzke-Kopp, L. M., Teti, D. M., \& Ammerman, R. T. (2014). Early adversity, RSA, and inhibitory control: Evidence of children's neurobiological sensitivity to social context. Developmental Psychobiology, 56, 964-978. DOI 10.1002/dev.21175

Skowron, E. A., Loken, E., Gatzke-Kopp, L. M., Cipriano-Essel, E. A., Woehrle, P. L., Van Epps, J.J., Gowda, A., \& Ammerman, R. T. (2011). Mapping cardiac physiology, parenting, and dyadic processes in maltreating mother-child dyads. Journal of Family Psychology, 25, 663-674. PMC3582338

Suchman, N. E., Pajulo, M., \& Mayes, L. C. (Eds.) (2013). Parenting and substance abuse: Developmental approaches to intervention. New York, NY: Oxford University Press.

Tarullo, A. R., \& Gunnar, M. R. (2006). Child maltreatment and the developing HPA axis. Hormones and Behavior, $50,632-639$.

Teicher, M., Samson, J., Anderson, C. \& Ohashi, K., (2016). The effects of childhood maltreatment on brain structure, function and connectivity. Nature Reviews Neuroscience, 17, 652-666. https://doi.org/10.1038/nrn.2016.111

Thomas, R., Abell, B., Webb, H., Avdagic, E., \& Zimmer-Gembeck, M. (2017). Parent-Child Interaction Therapy: A meta-analysis. Pediatrics, 140(3), e20170352. doi:10.1542/peds.2017-0352. 
Thomas, R., \& Zimmer-Gembeck, M. J. (2011). Accumulating evidence for parent-child interaction therapy in the prevention of child maltreatment. Child Development, 82, 177-192. doi.org/10.1111/j.14678624.2010.01548.x

Thomas, R., \& Zimmer-Gembeck, M. J. (2012). Parent-child interaction therapy: an evidence-based treatment for child maltreatment. Child maltreatment, 17, 253-266. doi.org/10.1177/1077559512459555

Trickett, P. K., Aber, J. L., Carlson, V., \& Cicchetti, D. (1991). Relationship of socioeconomic status to the etiology and developmental sequelae of physical child abuse. Developmental Psychology, 27(1), 148-158.

\section{doi.org/10.1037/0012-1649.27.1.148}

U.S. Department of Health \& Human Services, Administration for Children and Families, Administration on Children, Youth and Families, Children's Bureau. (2020). Child Maltreatment 2018. Available from https://www.acf.hhs.gov/cb/research-data-technology /statistics-research/child-maltreatment.

Vasquez, A. C., Patall, E. A., Fong, C. J., Corrigan, A. S., \& Pine, L. (2016). Parent autonomy support, academic achievement, and psychosocial functioning: A meta-analysis of research. Educational Psychology Review, $28(3), 605-644$.

Wells, J., N., Skowron, E., A., Scholtes, C., M., \& DeGarmo, D., S. (2020). Differential physiological sensitivity to child compliance behaviors in abusing, neglectful, and non-maltreating mothers. Development and Psychopathology, 32(2), 531-543. doi:10.1017/\$0954579419000270.

Wilson, S., Rack, J., Shi, X., \& Norris, A. (2008). Comparing physically abusive, neglectful, and nonmaltreating parents during interactions with their children: a meta-analysis of observational studies. Child Abuse \& Neglect, 32(9), 897-911. doi:10.1016/j.chiabu.2008.01.003.

Zisser, A., \& Eyberg, S. M. (2010). Parent-child interaction therapy and the treatment of disruptive behavior disorders. In J. R. Weisz \& A. E. Kazdin (Eds.), Evidence-based psychotherapies for children and adolescents (p. 179-193). The Guilford Press. 